\title{
Will highly educated women have more children in the future? In Southern Europe, it will largely depend on labour market conditions
}

\author{
Diego Ramiro-Fariñas, Francisco J. Viciana-Fernández and \\ Víctor Montañés Cobo*
}

The relationship between educational attainment and fertility dynamics has long been at the core of demographic and sociological studies, especially since the late 20th century, when the share of women with tertiary education expanded rapidly in advanced societies (Andersson et al. 2009). University educated women were forerunners in childbearing patterns that are commonplace today: the postponement of motherhood, childlessness, lowest-low fertility, and new partnership forms (Mills et al. 2011). However, recent studies have suggested that the negative educational gradient of fertility may be weakening or even disappearing, particularly in societies committed to reducing social and gender inequalities and supporting maternal employment and early childcare (Kravdal and Rindfuss 2008; Solera and Bettio 2013). The rapid spread of tertiary education among women has also altered traditional patterns of assortative mating (Esteve et al. 2012), and the reversal of the gender imbalance in education is affecting partnership and childbearing dynamics (van Bavel 2012). Furthermore, in most European countries, the effects of the recent economic crisis on the childbearing behaviour of women has varied across educational strata (Sobotka et al. 2011).

Spain is an interesting case study for examining the links between female education and fertility, because while Spain lagged behind the rest of Europe in

\footnotetext{
* Diego Ramiro-Fariñas (corresponding author), Institute of Economy, Geography and Demography, Spanish National Research Council, Center for Humanities and Social Sciences, C/ Albasanz, 26-28, $3^{\mathrm{a}}$ planta, módulo F, despacho 3F12, 28037 Madrid, Spain

Email: diego.ramiro@cchs.csic.es

Francisco J. Viciana-Fernández, Coordinador del Registro de Población, Servicio de Estadísticas Demográficas y Sociales, Institute of Statistics and Cartography of Andalusia, Leonardo Da Vinci, $\mathrm{n}^{\circ} 21$, Isla de La Cartuja, 41071 Seville, Spain Email: franciscoj.viciana@juntadeandalucia.es

Víctor Montañés Cobo, Institute of Statistics and Cartography of Andalusia, Leonardo Da Vinci, $\mathrm{n}^{\mathrm{o}} 21$, Isla de La Cartuja, 41071 Seville, Spain

Email: victor.montanes@juntadeandalucia.es
} 
terms of both the expansion of tertiary education and the timing of the first and second demographic transitions (Lesthaeghe 2014), these processes occurred at faster rates in Spain than they did in other countries once they had been set in motion. Looking at trends in female education, we observe that although less than $5 \%$ of Spanish women born in the 1930s had access to university education; by 2011, the proportion of Spanish women aged 25-34 with a university degree (44\%) exceeded that of their male counterparts (34\%). Indeed, women's educational advancement is one of the most striking social changes that have taken place in Spain in the last few decades. Similarly, when we look at trends in fertility, we find that Spain went from having the highest levels of fertility in Europe for much of the 20th century to being a forerunner in lowest-low and latest-late fertility by the end of that century. After reaching a historic low of 1.15 in 1998, the total fertility rate underwent a moderate recovery in the years that followed - which was then halted by the economic crisis. Although highly educated women were pioneers of late motherhood, fertility postponement is now a widespread pattern across all educational groups. The educational gradient of completed fertility has weakened, but remains negative (Castro-Martín and Martín-García 2013).

In order to examine in more detail how the educational gradient of fertility has changed over time, and particularly during the recent economic crisis, we analyse parity-specific fertility trends in a southern region of Spain, Andalusia. This region is the only one in Spain that has a longitudinal population database. With a population of about eight million (comprising 18 per cent of the total population of Spain), Andalusia is less developed than other regions in Spain, and has persistently high unemployment rates. Nevertheless, in recent decades the region has undergone a series of rapid economic, educational, and family-related changes. More than onethird of Spanish women born before 1935 were illiterate or had no formal education (Pérez Díaz 2007). But by 2011, more than 40 per cent of Spanish women aged 25-40 had a university degree. Historically, the period total fertility rate was higher in Andalusia than in the rest of Spain (by about 0.5 children per woman on average). However, the period TFR in the region has recently followed a path of decline similar to the decreasing trend in the rest of Spain, and has even converged to the national level, dropping from 3.1 in 1975 to 1.4 in 2014.

We first present an overview of the changing patterns of fertility by age and educational attainment based on an analysis of the Longitudinal Population Database of Andalusia 1998-2016 and the Sociodemographic Survey 1991, which provides a wealth of retrospective information that allow for the reconstruction of fertility by age, parity, and educational attainment from 1950 to 1991. Drawing upon these two sources, we are able to reconstruct parity progression ratios among women with different socioeconomic characteristics for a relatively long period of time. Using this approach, we can provide insights into the socio-demographic transformations that have taken place in an area of Europe not yet studied at this level of detail.

Figure 1 presents the parity progression rate to the first child by age and educational attainment in Andalusia from 1955 to 2011. We categorised educational 
Figure 1:

Parity progression rate: from childless to first child by age and educational attainment. Andalusia 1955-2011

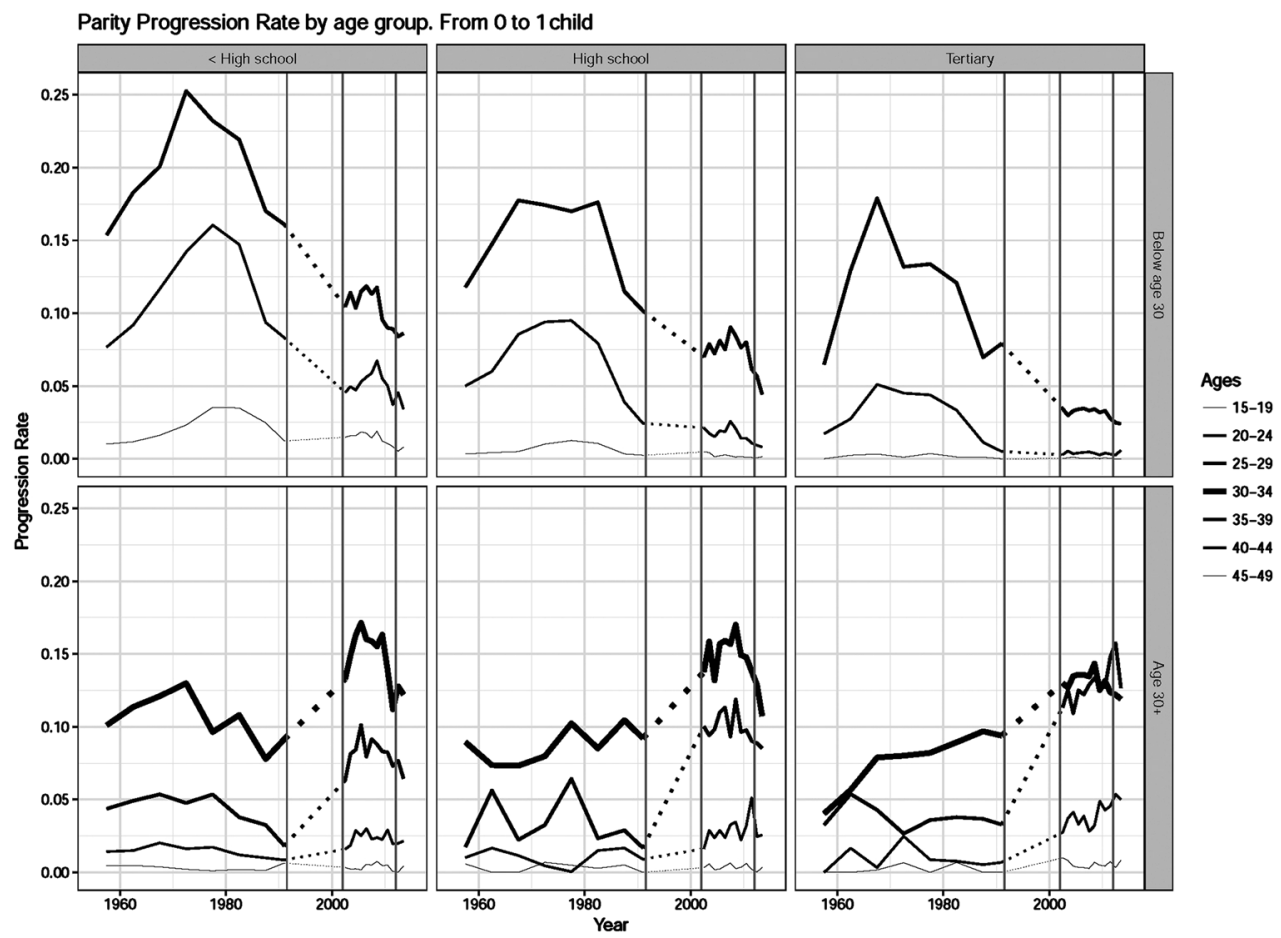

Source: Own elaboration from the 1991 Sociodemographic Survey of Spain and the Longitudinal Population Database of Andalusia.

attainment into three groups: lower than secondary, secondary, and tertiary education. The rate of transition to the first child declined sharply among university educated women in the younger age groups starting in 1970; whereas among the other educational groups, this decline occurred a decade later. Nevertheless, among women of all educational levels, the rate of progression to the first child increased in the older age groups, particularly starting in the late 1990s. These findings suggest that the postponement of motherhood has gradually become the norm across all social strata. Women with less than secondary schooling - an increasingly marginal group, since secondary education is compulsory and is fully subsidised in public schools - continue to be more likely than women with higher levels of education to have their first child at a relatively young age. For the large majority of better educated women, the transition to the first birth has increasingly shifted beyond age 30. These results suggest that the sizeable differences in fertility timing between educational groups that prevailed in the past have become smaller over the last 
Figure 2:

Parity- and age-adjusted total fertility rate (PATFR) by birth order (first and second births), education and employment. Andalusia 2002-2013
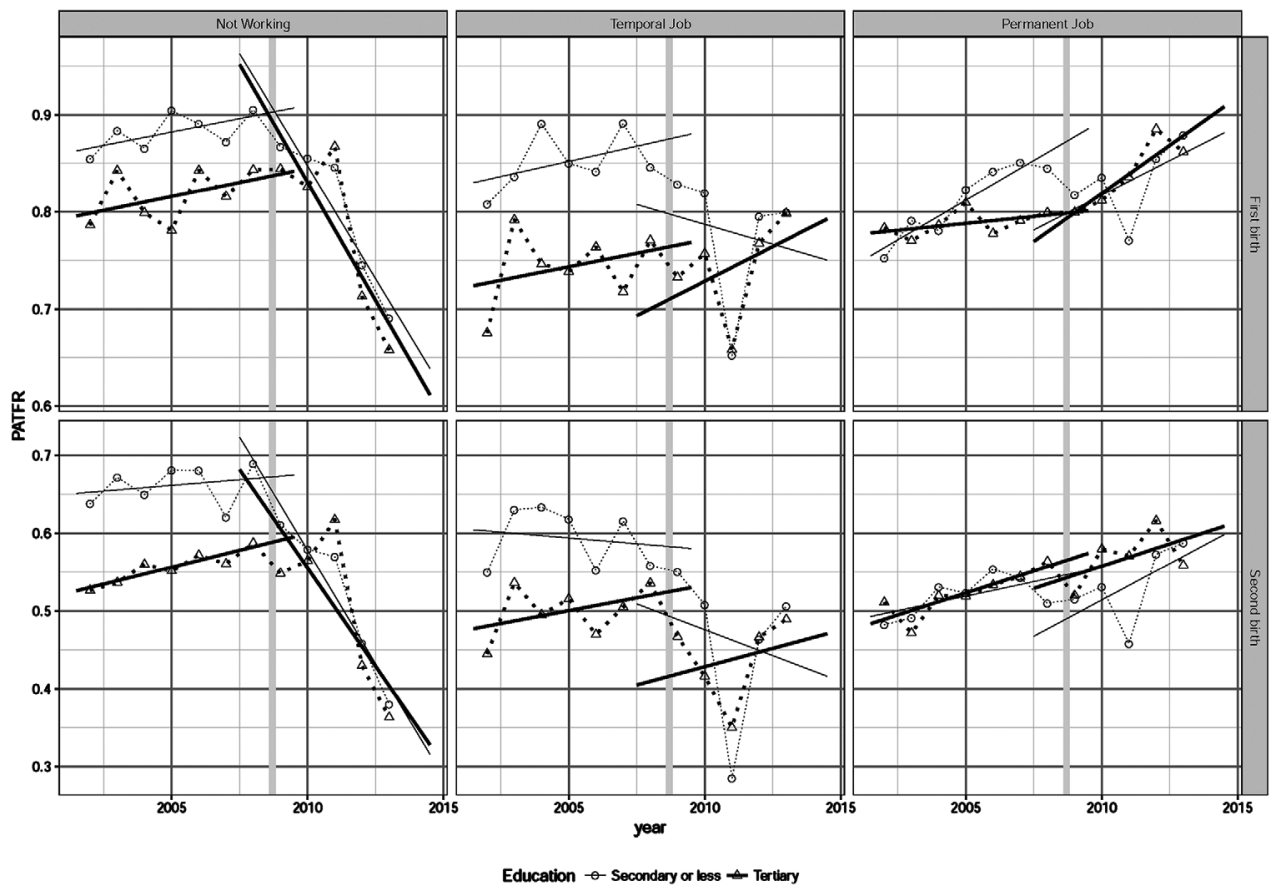

Source: Own elaboration from the Longitudinal Population Database of Andalusia.

two decades. During the recent economic crisis, the fertility patterns of highly educated women were the least affected; i.e. whereas among women with secondary education, the rate of transition to the first birth declined in all age groups; among women with tertiary education, the rate of transition to the first birth remained relatively stable.

In order to examine in more detail fertility patterns across educational groups in the most recent period and the intervening role of employment status, we use data from the Longitudinal Population Database of Andalusia. For the educational groups, we calculate parity- and age-adjusted fertility rates, as well as employment status at the time of the 2001 census. We distinguish between women who were not working, were in a temporary job, or were in a permanent job. The results are presented in Figure 2. After employment status is taken into account, the educational gradient for both first birth and second birth rates virtually disappears among women with a permanent job. During the economic crisis, fertility differentials by education narrowed among women who were not working or had a temporary work contract. Moreover, women who were not employed were the most affected by the economic 
crisis, as their fertility rates dropped considerably after 2008, regardless of their educational attainment. By contrast, women with a permanent job experienced a slight increase in fertility, again regardless of their educational attainment. Fertility differentials by education are found only among women with a temporary job, with less educated women experiencing a larger drop in fertility than their better educated counterparts. However, women in both educational groups who had a temporary job experienced a fertility recovery in the most recent years.

In sum, although the negative educational gradient of fertility persists in Spain, it has weakened considerably in recent decades. Moreover, the differential impact of the economic crisis on the fertility behaviour of various educational groups has not only further weakened the traditional educational gradient; it has shown that the impact of employment on fertility is much stronger than that of educational attainment. During the decade-long economic crisis, unemployed women, regardless of their educational attainment, have reduced their fertility. By contrast, during the same period, both less educated and more educated women with a permanent job have slightly increased their fertility. Our observation that employment status influences reproductive decision-making more than educational attainment is consistent with the findings of other studies (Adsera 2011; EspingAndersen 2007; Esping-Andersen et al. 2002).

In the near future, if there is a positive shift in the economy and a considerable reduction in unemployment and temporary employment, women with secondary education or less could experience a recuperation of the fertility postponed during the economic crisis. However, this is not the most likely scenario in the short term, especially considering that in Spain, large shares of the population are neither in employment nor in education or training (NEET); of young adults aged 20 24, 30 per cent are in the NEET category (OECD 2015). Among Andalusian women aged 25-44, the unemployment rate is 45 per cent for those with secondary education or less, and is 25 per cent for those with tertiary education. Furthermore, the share of workers with a permanent job has been rapidly declining, especially among the lower educated population. In light of these trends, the potential for an increase in fertility is low for all educational groups.

\section{Acknowledgements}

This manuscript has been created as part of the LONGPOP project. The LONGPOP project has received funding from the European Commissions, within the Horizon 2020 Research and Innovation programme under Marie Sklodowska-Curie grant agreement No. 676060.

\section{References}

Adsera, A. 2011. Where are the babies? Labor market conditions and fertility in Europe. European Journal of Population 27(1): 1-32. 
Andersson, G., L. B. Knudsen, G. Neyer, K. Teschner, M. Rønsen, T. Lappegård, K. Skrede and A. Vikat 2009. Cohort fertility patterns in the Nordic countries. Demographic Research 20(14): 313-352. DOI: 10.4054/DemRes.2009.20.14.

Castro-Martín, Teresa and Teresa Martín-García 2013. The fertility gap in Spain: Late parenthood, few children and unfulfilled reproductive desires. In The fertility gap in Europe: Singularities of the Spanish case, ed. Gøsta Esping-Andersen, 45-81. Social Studies Collection, 36. Barcelona: Fundación La Caixa.

Esping-Andersen, G. 2007. Family formation and family dilemmas in contemporary Europe. Bilbao Spain: Fundación BBVA. ISBN 9788496515352.

Esping-Andersen, G., D. Gallie, A. Hemerijck and J. Myles 2002. Why we need a new welfare state. Oxford: Oxford University Press.

Esteve, A., R. Lesthaeghe and A. López-Gay 2012. The Latin American cohabitation boom, 1970-2007. Population and Development Review 38(1): 55-82.

DOI: $10.1111 / \mathrm{j} .1728-4457.2012 .00472 . x$.

Kravdal, Ø. and R. R. Rindfuss 2008. Changing relationships between education and fertility: A study of women and men born 1940 to 1964. American Sociological Review 73(5): 854-873. Stable URL: http://www.jstor.org/stable/25472561.

Lesthaeghe, Ron 2014. The second demographic transition: A concise overview of its development. PNAS 111(51): 18112-18115. DOI: 10.1073/pnas.1420441111.

Mills, M., R. R. Rindfuss, P. McDonald and E. Velde 2011. Why do people postpone parenthood? Reasons and social policy incentives. Human Reproduction Update 17(6): 848-860. DOI: 10.1093/humupd/dmr026.

OECD 2015. Education at a Glance 2015. OECD Indicators. OECD Publishing. DOI: 10.1787/eag-2015-en.

Pérez Díaz, J. 2007. La revolución educativa en las generaciones españolas. Revista de Demografía Histórica XXV(I): 137-163.

Sobotka, T. 2004. Is lowest-low fertility in Europe explained by the postponement of childbearing? Population and Development Review 30(2): 195-220.

DOI: 10.1111/j.1728-4457.2004.010_1.x.

Sobotka, T., V. Skirbekk and D. Philipov 2011. Economic recession and fertility in the developed world. Population and Development Review 37(2): 267-306. DOI: 10.1111/j.1728-4457.2011.00411.x.

Solera, C. and F. Bettio 2013. Women's continuous careers in Italy: The education and public sector divide. Population Review 52(1): 129-148.

Van Bavel, J. 2010. Choice of study discipline and the postponement of motherhood in Europe: The impact of expected earnings, gender composition and family attitudes. Demography 47(2): 439-458.

Van Bavel, J. 2012. The reversal of gender inequality in education, union formation, and fertility in Europe. Vienna Yearbook of Population Research 10: 127-154. 